\title{
Structural Behaviour and Mechanical Properties of Welded Steel I- Girders with Corrugated Webs
}

\author{
Xuqun Lin, Harry Far ${ }^{*}$, Ali Saleh \\ School of Civil and Environmental Engineering, Faculty of Engineering and Information Technology, University of Technology \\ Sydney (UTS), Australia
}

\begin{abstract}
Steel I girders with corrugated webs are appropriate alternatives for normal flat-web girders in steel structures since they provide lighter and smaller beam features in steel design. Based on the existing literature, the corrugated web beams (CWBs) provide many advantages for structural applications. In this study, a series of numerical analyses have been performed in order to investigate the structural behaviour of steel I girders with corrugated web profile and to compare their mechanical performance with normal welded beams. Theory of Ultimate Limit State design has been adopted in accordance with AS4100 (1998) along with considering geometric and material non-linearity in the numerical analyses in SAP2000. Comparing the results of the numerical investigation, merits of using corrugated welded beams (CWBs) over normal welded beams (WBs) have become apparent. Moreover, investigations regarding force-displacement relationship and buckling analysis of the webs were carried out and presented to further validate the advantages of using corrugated web beams. CWBs have been used in some parts of Australia without detailed information about their mechanical properties. Thus, based on the outcomes of this study, CWB table for dimensions and cross sectional properties has been developed and proposed for practical applications.
\end{abstract}

Keywords: Mechanical Properties; Corrugated Web Beams; Optimisation; SAP2000; Ultimate Limit State Design

\section{Introduction and Background}

Steel I girders with corrugated webs are appropriate alternatives for ordinary steel girders in steel structures. According to Abbas et al. (2006), mechanical properties of corrugated web beams were investigated back in the 1960s. Those beams have been used widely after the 1980s in European countries. The use of corrugated-web beams has become popular as part of steel structures in many countries, e.g. Austria, China, Japan, and US (Dubina et al. 2015). According to available literature, corrugation size distribution in webs significantly influences the shear and flexural strengths of corrugated steel beams (e.g. Alandkar \& Limaye 2013; Abbas et al. 2006; Divaha \& Joanna 2016; Ashrawi et al. 2016; Elgaaly et al. 1997). Ashrawi et al. (2016) pointed out that the web corrugation can increase both shear and flexural strengths compared to conventional beams with the same dimensions. Additionally, the stability of the web against buckling will be improved when larger loads apply to the beam.

Nonlinear finite element analysis enables designers to carry out more accurate comparison of the structural properties between CWB's and flat-web beams. In ordinary steel beams, the web is a critical load-carrying component which may be susceptible to local buckling as well as overall lateral buckling of the beam. Consequently, the beam capacity may be governed by the web thickness (Huang et al. 2004). To overcome this shortcoming of ordinary steel beams, corrugated web beams (CWBs) can be employed in building design. In building design, beams are the significant elements to support each floor and transmit loads to columns (Walsh et al. 2018). Transmitted loads then will be transferred to the foundation. A primary building design consideration is to reduce the self-weight of structures achieved by designing beams with shorter and thinner webs (Tabatabaiefar et al., 2015; Tabatabaiefar and Mansoury, 2016). Therefore, corrugated web beams (CWBs) can be considered suitable alternatives for flat-web beams to achieve this goal.

Ju et al. (2014) stated that CWBs are built-up systems of flat flanges and web with thin corrugations. Figure 1 shows an example of CWBs in a high-way bridge. The corrugation profile provides more stiffness against local buckling so that the strength capacity can be increased. Corrugated beams also deform less than ordinary beams due the increase in overall stiffness of the beam which can reduce total deflection of the structure (Ju et al. 2014).

According to Ju et al. (2014), traditional design of steel beams in practice can result in the following issues:

- Failure of the standard beam caused by lateral torsional buckling; and

- The inability of the flat web to provide enough shear resistance when it is subjected to high shear stress. 


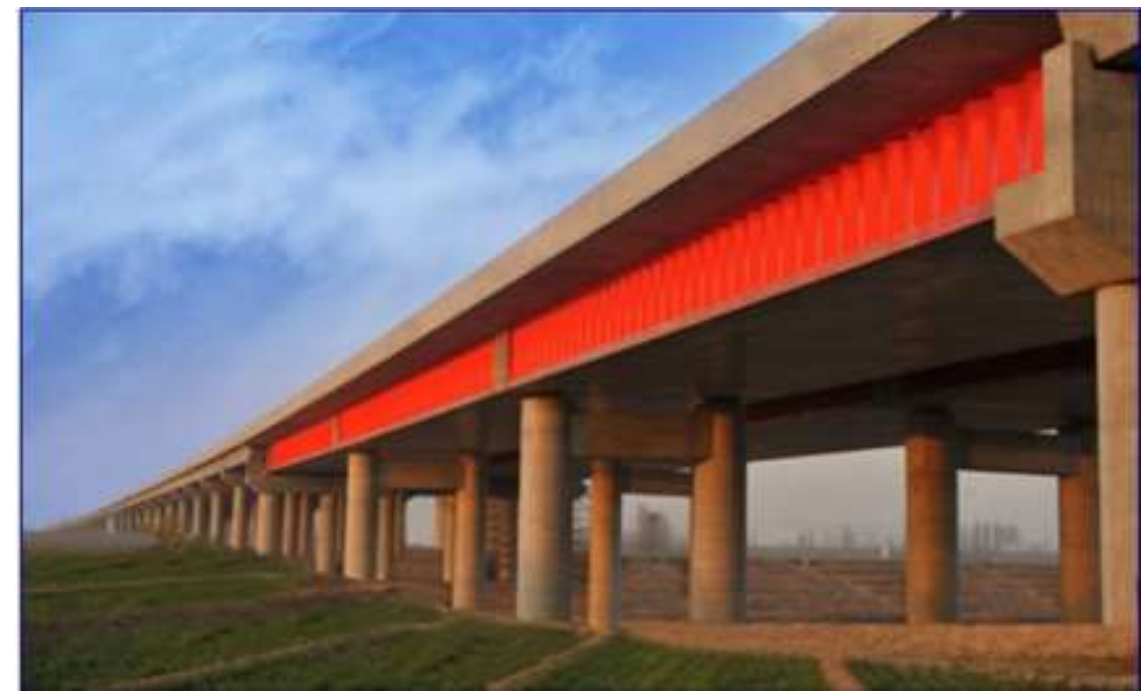

Figure 1. CWBs in a high-way bridge (Tang \& Wan 2010).

When the corrugation is applied to the web of the beams, the flexural and shear strengths of the beams will be significantly improved. Dunai et al. (2016) conducted comprehensive numerical investigation of the flexural strength of CWBs. They pointed out that the flexural capacity of CWBs is significantly (up to 20\%) higher than the flat-web beams. They also realised that if the interaction of bending and shear is considered, the flexural strength may be reduced by 3 $4 \%$ but CWBs still perform better than the normal beams in resisting buckling of the web. They concluded that utilisation of corrugations in the webs is a useful technique to increase the performance of the conventional beams in steel structures. Hancock and Pham (2012) presented several experiments to estimate the shear strength of some CWBs. In those experiments, the linear structural model was adopted and only the elastic aspects of the CWBs were considered. They summarised the shear properties and presented several equations for the shear strength with a high coefficient of variation. Dubina et al. (2015) carried out several tests on CWBs with five different thickness values for the web. They reported that the corrugation of webs can stiffen the web which leads to increase in shear strength of CWBs with a material saving of $15-30 \%$ while the traditional beams need to be restrained by web stiffeners to carry the same loads.

Several researchers (Abbas et al., 2003; and Yazzed 2007; Lukin and Shlyakhin 2016) focused on the analysis of the elastic behaviour of CWBs. They utilised a comprehensive investigative process to predict the shear strength of CWBs. However, according to Kovesdi (2010), many of those researchers overestimated the shear strength by using linear analysis. In their assumptions, they did not pay attention to corrugation size of the webs while the consideration of corrugation size was necessary. Nevertheless, all the above-mentioned researchers performed functional research to estimate the properties of CWBs, they only focused on the elastic analysis in establishing the properties of CWBs which may overestimate the results. In addition, those research works adopted the linear-analysis method (and not the nonlinear method) for investigating the performance of CWBs under different types of loads.

CWBs have been used in some parts of Australia without detailed information about their mechanical properties. While AS 4100 (1998), the steel structures standard in Australia, states all the necessary structural requirements in the steel design field, it does not include a distinct section covering design and construction aspects of CWBs. Therefore, a reasonably adequate table of mechanical properties for corrugated-web beams is required to introduce mechanical properties of this type of beams to Australian engineering community.

\section{Methodology}

Using SAP2000 non-linear finite element analysis software (Computers and Structures 2018), a comprehensive numerical investigation was carried out in this study in order to determine mechanical properties of CWBs with the most optimum corrugation size and web thickness. Using the cross-section geometry and properties of the welded beams listed in the Hot Rolled and Structural Steel Products property tables (2018) as a starting point, the aim was to minimise mass and section depth of the CWBs while maintaining the stiffness and strength about the major bending axis of the parent WBs. The present study focuses on CWB applications where the design ensures that the compression flange, being top flange, is fully restrained and hence lateral torsional buckling is prevented. Applications where the compression flange is unsupported can be designed in the usual way as other WB's. Elastic buckling analyses were also performed to ensure safety against local buckling, especially in the web and it was found that all buckling load factors were greater than 1.0 based on each CWB's design load combination for flexural strength in accordance with AS/NZS 1170.1 (2002). Based on the optimised results of this study, the most common cases of CWBs were selected in order to propose a detailed table of mechanical properties of CWBs for practical purposes. 


\subsection{CWB Geometry}

All the CWB models in this study are designed based on Hot Rolled and Structural Steel Products property tables for welded beams (2018) by replacing their flat webs with corrugated webs. As shown in an example in Figure 2, the shape of the web is defined by a sine curve with the amplitude of $A$ and the wave length of $L$. Moreover, the relationship between amplitude $A$ and corrugation angle $\theta$ at the centreline of the web is given by $A=L / 4 \times \tan (\theta)$. Using numerical simulation, the optimum combination of corrugation length $L$ and angle $\theta$ were found iteratively by trial and error.

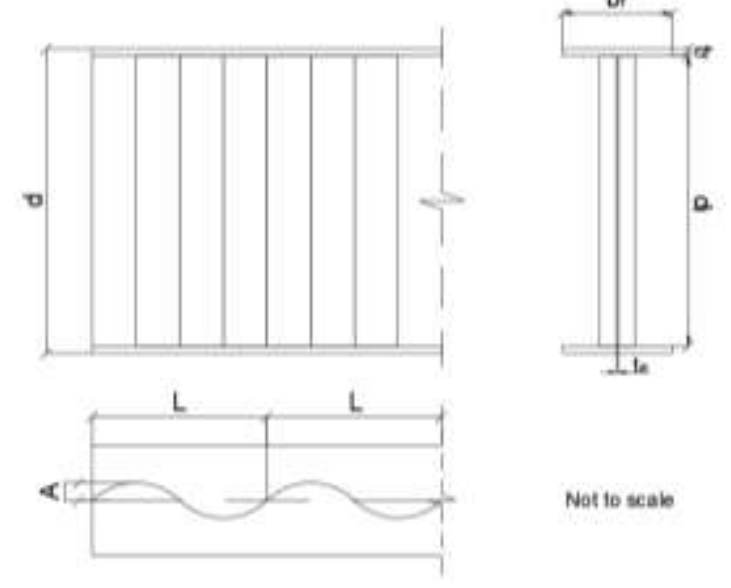

Figure 2. Sample elevation of a CWB.

\subsubsection{Numerical Simulation Assumptions}

All simulations were carried out using SAP2000 finite element software. A typical finite element mesh is shown in Figure 3, and the following points were taken into consideration.

- Since span length of ordinary steel beams, used in the building industry, is typically in the range 3 to 7 metres, the median length of 5 metres was selected as the beam span length in all numerical simulations.

- In the FE simulation standard shell elements available in SAP2000 were used to model the webs, flanges and end stiffeners. Typical FE model details are depicted in Figures 3 and 4.

- All the CWBs were modelled as simply supported, with the critical top flange restrained against lateral buckling. As a result, the member flexural capacity will be equal to the section flexural capacity.

- As illustrated in Figure 4, modelling of the pin and roller supports was by constraining the nodes of the stiffner plates at both end of the beam at the stiffener's mid-depth. This modelling provided also a twisting constraint at both ends of the beam. To prevent rigid body displacment along the beam's axis, the same stiffener nodes were also constrained at only one beam end in the beam's longitudinal direction.

- The beams were subjected to a uniformly distributed load applied in the FE model as a constant pressure to the top flanges.

- Non-linear analysis has been adopted and the stress levels were checked to ensure they were below 0.9fy.

- Imperfection is deemed of second order and therefore has not been considered in numerical modelling.

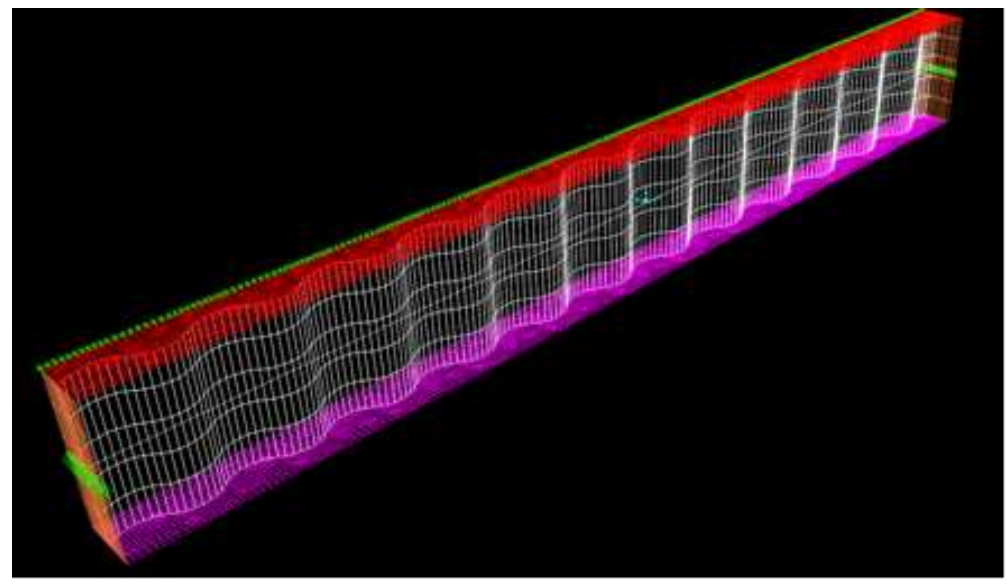

Figure 3. Illustration of a 3-D beam model with end stiffeners 


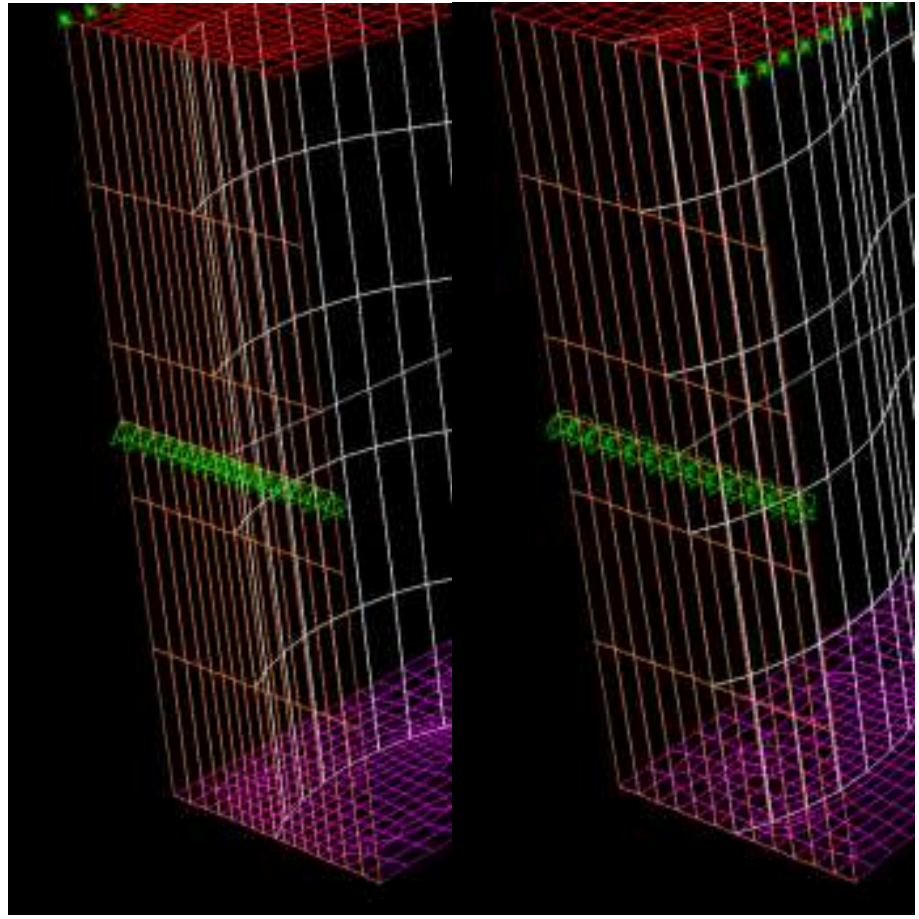

Figure 4. Details of pin supports and roller supports at beam ends

\subsubsection{Design and Analysis Parameters}

For each CWB, the uniformly distributed load $w$, which the beam can safely carry, was taken as the distributed load required for the corresponding parent WB with flat web to reach its ultimate moment capacity for bending about the major principal axis. Adopting the Ultimate Limit State (ULS) design theory according to AS4100 (1998), the ultimate moment capacity is reached when the normal stress $\sigma$ in the extreme fibre reaches the value of $\sigma=\Phi f_{y}$, where the capacity reduction factor $\Phi$ is equal to 0.9 and $f_{y}$ is the yield stress.

The extreme fibre stress is equal to

$\sigma=M y / I$

where, $I$ is the second moment of inertia and $y$ is the distance from the centroid axis to the top fibre of the beam. The mid-span moment $M$ of a simply supported beam of length $L$ is given by

$M=w^{*} L^{2} / 8$

From equations 1 and 2 , the load $w$ can be extracted as follows:

$w^{*}=14.4 f_{y} \times I /\left(d \times L^{2}\right)$

The value of $w^{*}$ established in equation (3) is assumed to represent the design load combination for flexural strength in accordance with AS/NZS $1170.1(2002)$ in the form of $w^{*}=(1.2 \mathrm{DL}+1.5 \mathrm{LL})$, with DL and LL representing respectively Dead Load and Live Load. Assuming DL $=3$ LL leads consequentially to DL $=w^{*} / 1.7$ and $L L=w^{*} / 5.1$ and thereby enable the analysis of an additional load case to ensure satisfying the deflection limit states for the design load case of AS/NZS 1170.1 given by $w^{\Delta}=(\mathrm{DL}+0.7 \mathrm{LL})$, which equates to $w^{4}=0.725 w^{*}$.

\subsection{Material Properties}

Two types of structural steel grades have been utilised in this study, including 300PLUS-300 and 300PLUS-280 as shown in Table 1. The mass density of structural steel is equal to $7849 \mathrm{~kg} / \mathrm{m}^{3}$. The set of properties for 300PLUS-300 are: Minimum yielding stress $f_{y}=300 \mathrm{MPa}$; Minimum tensile stress $f_{u}=440 \mathrm{MPa}$; Elastic modulus $E=200,000 \mathrm{MPa}$; Shear modulus $G=82 \mathrm{MPa}$. The set of properties for 300PLUS-280 are: Minimum yielding stress $f_{y}=280 \mathrm{MPa}$; Minimum tensile stress $f_{u}=440 \mathrm{MPa}$; Elastic modulus $E=200,000 \mathrm{MPa}$; Shear modulus $G=82 \mathrm{MPa}$. In this study, the maximum flexural stress of 300PLUS-300 steel was $300 * 0.9=270 \mathrm{MPa}$, and the maximum shear stress was $270 * 0.6=162 \mathrm{MPa}$. Similarly, the maximum flexural stress of 300PLUS-280 steel was $252 \mathrm{MPa}$ and the maximum shear stress was 151.2 MPa. As a result, during the optimisation process, the stress level should not exceed these limits. 
Table 1. Illustrations of Material types of WB beams.

\begin{tabular}{|c|c|}
\hline Designation & Material Type \\
\hline $700 W B 115$ & 300PLUS-300 \\
\hline $700 W B 130$ & 300PLUS-300 \\
\hline $700 W B 150$ & 300PLUS-280 \\
\hline $700 W B 173$ & 300PLUS-280 \\
\hline $800 W B 122$ & 300PLUS-300 \\
\hline $800 W B 146$ & 300PLUS-300 \\
\hline $800 W B 168$ & 300PLUS-280 \\
\hline $800 W B 192$ & 300PLUS-280 \\
\hline $900 W B 175$ & 300PLUS-300 \\
\hline $900 W B 218$ & 300PLUS-280 \\
\hline $900 W B 257$ & 300PLUS-280 \\
\hline $900 W B 282$ & 300PLUS-280 \\
\hline $1000 W B 215$ & 300PLUS-300 \\
\hline $1000 W B 258$ & 300PLUS-280 \\
\hline $1000 W B 296$ & 300PLUS-280 \\
\hline $1000 W B 322$ & 300PLUS-280 \\
\hline $1200 W B 249$ & 300PLUS-280 \\
\hline $1200 W B 278$ & 300PLUS-280 \\
\hline $1200 W B 313$ & 300PLUS-280 \\
\hline $1200 W B 342$ & 300PLUS-280 \\
\hline 1200WB392 & 300PLUS-280 \\
\hline $1200 W B 423$ & 300PLUS-280 \\
\hline $1200 W B 455$ & 300PLUS-280 \\
\hline
\end{tabular}

\section{Validation of the Developed Numerical Model}

Many researchers (e.g. Martins et al. 2012; Calenzani et al. 2012; Oliveira et al. 2016) performed functional experimental and numerical studies on structural behaviour of steel beams with corrugated web. To validate the accuracy of the numerical model developed in this study, the numerical results have been validated against the results of physical tests performed by Martins et al. (2012). Martins et al. (2012) experimental program consisted of tests carried out on three full-scale composite connections in cruciform arrangement. The sinusoidal-web beams used in their study were PSS $600 \times 150 \times 12.5 \times 2.0$ for specimens 1 and 2 and PSS $600 \times 150 \times 8 / 12.5 \times 2.0$ for specimen 3 . Specimen 1 has been selected for numerical verification due to having similar characteristics with the numerical model developed in this study. The experimental beam was modelled using the same FE approach with shell elements as was used in this study. The load-deflection curves in Figure 5 compare the experimental curve reported by Martins et al. (2012) with the FE results obtained using the same approach adopted to model the CBW's investigated in this study.

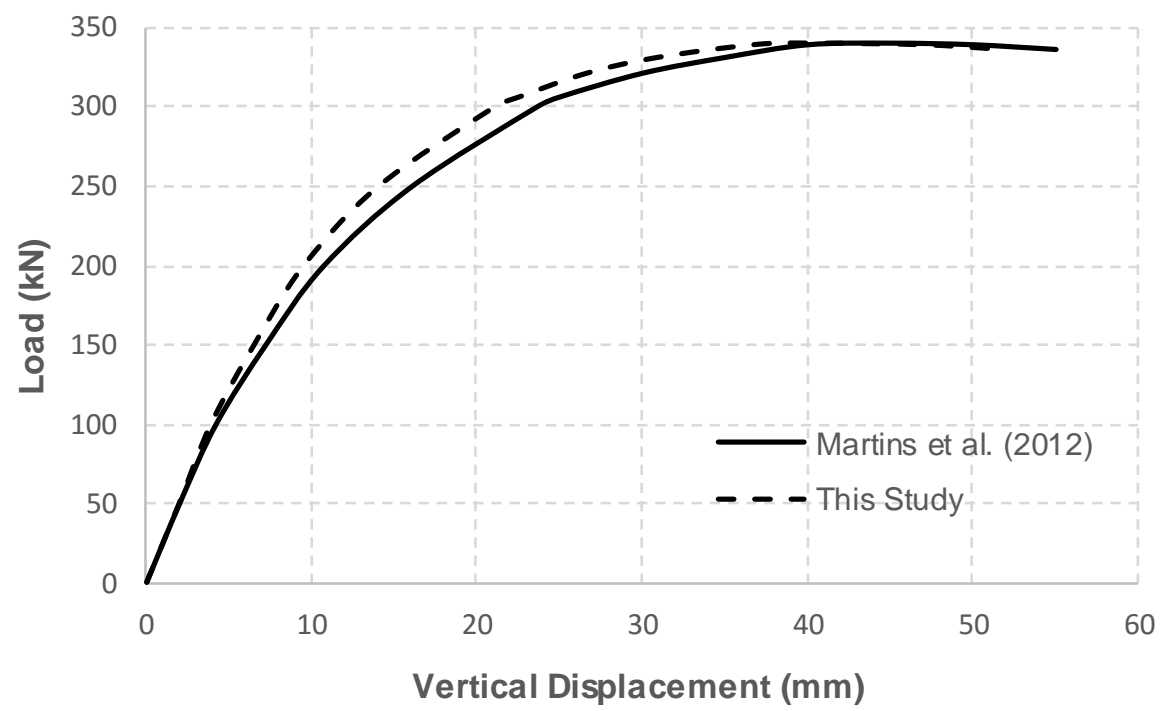

Figure 5. Load-deflection curves estimated by the numerical model developed in this study with the experimental data reported by Martins et al. (2012). 
Considering the reported results in Figure 5, it has become apparent that the trends and the values of the numerical responses, predicted by the developed SAP2000 numerical model in this study, are in good agreement and consistent with the experimental data reported by Martins et al. (2012). Therefore, the developed numerical model in this study can replicate the behaviour of real steel corrugated web beams with acceptable accuracy. The good agreement between the numerical predictions and the experimental data proves the validity of the current developed numerical model. As a result, predictions provide confidence in the practical utility of the developed model.

\section{Numerical Parametric Study on Corrugation Sizing}

All analyses have incorporated geometric nonlinearity to achieve greater accuracy, as Jiang et al. (2015) pointed out that the consideration of the geometric nonlinearity would reduce the flexural strength of the CWBs by approximately $4.2 \%$. To select the most efficient CWB cross section geometry corresponding to each parent WB, the following two-stage approach was adopted.

First the corrugation angle was kept constant at $\theta=30^{\circ}$ and the beams were analysed for corrugation lengths of $320 \mathrm{~mm}$, $400 \mathrm{~mm}$, and $500 \mathrm{~mm}$, while maintaining the original web depth. Based on the results in Table 2, the 400mm corrugation length showed the best performance by having the lowest stress and deflection values and was therefore adopted for all subsequent analyses.

Table 2. Comparison of CWBs and normal 700WB115 regarding corrugation length

\begin{tabular}{c|cccc} 
Designation & Deflection $(\mathrm{mm})$ & S11(MPa) & S12(MPa) & $\mathrm{m}(\mathrm{kg})$ \\
\hline Normal beam & 11.5 & 268.3 & 146 & 579 \\
400 mm length CWB & 8.24 & 205.2 & 125.2 & 591.60 \\
320mm length CWB & 8.3 & 207.4 & 129.2 & 591.54 \\
500mm length CWB & 8.23 & 205.6 & 127.5 & 591.61
\end{tabular}

Keeping the $400 \mathrm{~mm}$ corrugation length constant the standard 700WB115 beam was analysed for corrugation angles $\theta$ of 15, 20, 25, and 30 degrees. For each angle web depth and web thickness were progressively reduced until the strength limit state was approached. In each case, both the flexural stress $S 11$ in the flanges and the web shear stress $S 12$ were checked respectively at mid-span and near the supports. From the results presented in Table 3, it was found that the corrugation angle $\theta=20^{\circ}$ has the best overall performance by giving the highest reduction in mass of $16 \%$ approximately.

Table 3. 700CWB115 Beam performances with different corrugation angle with $400 \mathrm{~mm}$ corrugation length

\begin{tabular}{c|cccccccc}
\multicolumn{1}{c}{ Designation } & $\begin{array}{c}\text { Deflection } \\
(\mathrm{mm})\end{array}$ & S1I(MPa) & S12(MPa) & $m(\mathrm{~kg})$ & $\begin{array}{c}\text { Section } \\
\text { Depth }(\mathrm{mm})\end{array}$ & $\begin{array}{c}\text { Mass Reduction } \\
(\%)\end{array}$ & $\begin{array}{c}\text { Depth Reduction } \\
(\%)\end{array}$ \\
\hline Normal beam & 11.5 & 268.3 & 146 & 579.03 & 692 & N/A & N/A \\
15-degree CWB & 11.4 & 267 & 161.3 & 500.53 & 556.8 & 13.56 & 19.54 \\
20-degree CWB & 11.8 & 266.5 & 161 & 486.62 & 556.8 & 15.96 & 13.28 & 19.54 \\
25-degree CWB & 11.7 & 268.3 & 162 & 502.15 & 556.8 & 15.66 & 19.54 \\
30-degree CWB & 12.2 & 268.4 & 162 & 488.37 & 556.8 & &
\end{tabular}

For the optimised CWBs, the reduction in total section depth of approximately $20 \%$ was associated with lower values of $I$ and consequently slightly higher deflections of between $2 \%$ and $6 \%$ as can be seen in Table 3 in comparison with the normal beam. For the applied loading, the extreme fibre flexural stress (S11) was virtually the same for the optimised and the normal beam as can be seen in Table 3. It is noted that for the particular distributed load applied, the stress limit state of $0.9 f_{y}=270 \mathrm{MPa}$ was not exceeded, which was the mechanism of the optimisation process used to reduce the weight of the CWBs.

\section{Optimisation of Australian Welded Beam Table}

Using SAP2000 finite element software, the standard steel welded beam sections (WBs) listed in the Hot Rolled and Structural Steel Products property tables for welded beams (2018) were analysed after replacing their flat webs with corrugated webs and optimising the corrugation geometry for reduced mass and web depth. The CWBs were modelled with the corrugation size determined from Section 3, whereby based on the results obtained from a parametric study on 
the 700WB115, the 400mm corrugation length and 20-degree corrugation angle were adopted for all other CWB sections. A summary of important analysis results for each of the CWB's can be found in Table 4.

\subsection{Stress and Buckling Analysis}

Comparing the numerical analysis results in Table 4, it has become apparent that the optimised CWBs carry slightly higher level of flexural stress due to significant reduction in web depth compared to standard WBs. An example of the section depth reduction is shown in Figure 6. Although due to the reduction in section depth the calculated CWB deflections were found to be higher than the WBs as predicted before, none of the deflection values exceeded the maximum allowable deflection of $L / 250$ prescribed by AS4100 (1998).

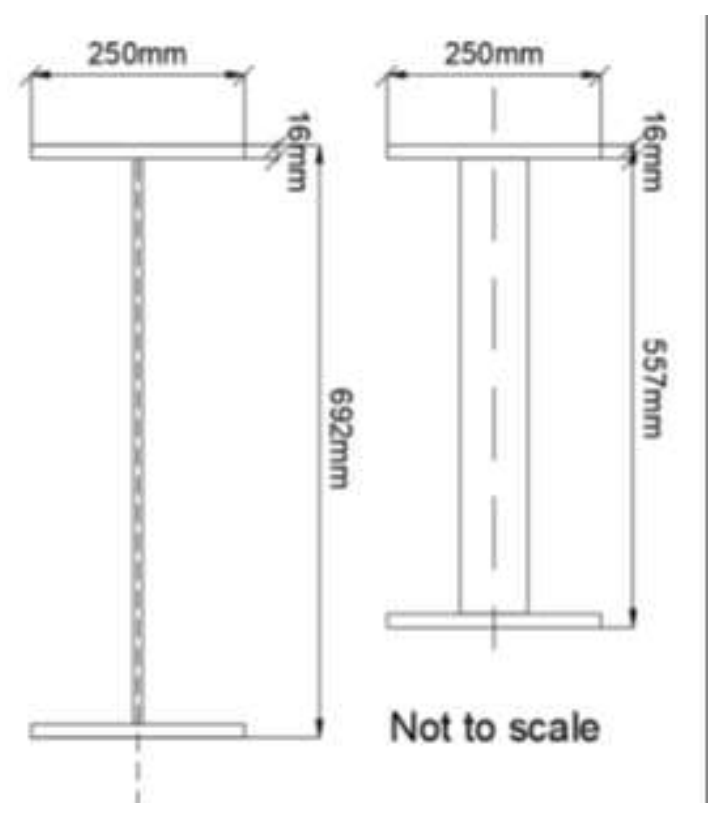

Figure 6. Difference in the height of 700CWB115 after the optimision

Table 4. Mechanical performance comparison of WBs and optimised CWBs

Standard WBS

Optimised CWBS

\begin{tabular}{|c|c|c|c|c|c|c|c|c|c|c|c|c|}
\hline Designation & $\omega *(k N / m)$ & $\Delta(\mathrm{mm})$ & S11(MPa) & S12(MPa) & $\mathrm{W}(\mathrm{kg})$ & $\Delta(\mathrm{mm})$ & S11(MPa) & $\mathrm{S} 12(\mathrm{MPa})$ & $\mathrm{W}(\mathrm{kg})$ & $\begin{array}{l}\text { Section } \\
\text { Depth } \\
(\mathrm{mm})\end{array}$ & $\begin{array}{c}\text { Height } \\
\text { Reduction } \\
(\%)\end{array}$ & $\begin{array}{c}\text { Mass } \\
\text { Reduction } \\
(\%)\end{array}$ \\
\hline $700 W B 115$ & 287.17 & 11.50 & 268.3 & 146.0 & 572.98 & 11.8 & 266.5 & 161 & 479.50 & 556.8 & 19.54 & 16.3 \\
\hline $700 W B 130$ & 345.60 & 11.30 & 268.4 & 146.5 & 651.47 & 11.9 & 268.4 & 161.9 & 517.83 & 562.0 & 19.71 & 20.5 \\
\hline $700 W B 150$ & 388.43 & 10.50 & 251.7 & 148.3 & 749.58 & 12 & 269.1 & 151.2 & 617.63 & 571.0 & 19.58 & 17.6 \\
\hline $700 W B 173$ & 464.02 & 10.40 & 251.6 & 148.0 & 863.39 & 12.1 & 250.1 & 151.1 & 727.10 & 576.4 & 19.50 & 15.8 \\
\hline $800 W B 122$ & 342.55 & 10.03 & 269.1 & 147.6 & 612.22 & 10.5 & 269.8 & 161.3 & 486.92 & 635.8 & 19.72 & 20.5 \\
\hline $800 W B 146$ & 440.64 & 9.93 & 269.3 & 147.3 & 729.96 & 10.7 & 267.8 & 161.8 & 601.15 & 643.0 & 19.63 & 17.6 \\
\hline $800 W B 168$ & 493.80 & 9.16 & 251.4 & 147.2 & 837.88 & 10.6 & 251.2 & 150.6 & 688.97 & 651.0 & 19.63 & 17.8 \\
\hline $800 W B 192$ & 587.01 & 9.09 & 251.6 & 148.7 & 957.58 & 10.5 & 250.5 & 150.8 & 803.78 & 656.4 & 19.56 & 16.1 \\
\hline $900 W B 175$ & 568.32 & 8.83 & 269.3 & 150.1 & 875.95 & 8.8 & 268.8 & 161.4 & 700.17 & 722.0 & 19.78 & 20.1 \\
\hline $900 W B 218$ & 719.56 & 8.15 & 250.3 & 140.3 & 1091.80 & 8.9 & 250.7 & 150.7 & 904.86 & 731.0 & 19.67 & 17.1 \\
\hline $900 W B 257$ & 889.15 & 8.10 & 251.6 & 147.5 & 1284.10 & 9.2 & 252 & 150.6 & 1058.55 & 735.4 & 19.72 & 17.6 \\
\hline $900 W B 282$ & 1000.15 & 8.03 & 250.8 & 149.5 & 1409.68 & 9.3 & 251.2 & 151.1 & 1186.13 & 742.6 & 19.63 & 15.9 \\
\hline
\end{tabular}




\begin{tabular}{|c|c|c|c|c|c|c|c|c|c|c|c|c|}
\hline $1000 W B 215$ & 701.57 & 7.95 & 268.7 & 149.7 & 1073.74 & 6.9 & 269.9 & 161.8 & 859.01 & 802.0 & 19.80 & 20.0 \\
\hline $1000 W B 258$ & 867.08 & 7.34 & 251.4 & 141.2 & 1289.59 & 6.8 & 251.6 & 149.9 & 1066.76 & 811.0 & 19.70 & 17.3 \\
\hline $1000 W B 296$ & 1055.62 & 7.30 & 251.1 & 145.7 & 1481.89 & 7.2 & 251.2 & 150.7 & 1251.52 & 816.4 & 19.65 & 15.5 \\
\hline $1000 W B 322$ & 1178.10 & 7.24 & 251 & 148.3 & 1607.48 & 7.1 & 251.1 & 150.8 & 1345.57 & 822.6 & 19.67 & 16.3 \\
\hline $1200 W B 249$ & 879.46 & 6.34 & 251.2 & 148.7 & 1242.89 & 6.6 & 250.8 & 151.1 & 1006.60 & 939.0 & 19.74 & 19.0 \\
\hline $1200 W B 278$ & 1049.01 & 6.34 & 251.4 & 143.4 & 1390.06 & 6.8 & 250.9 & 150.8 & 1143.14 & 939.0 & 19.74 & 17.8 \\
\hline $1200 W B 313$ & 1268.57 & 6.31 & 250.8 & 146.5 & 1582.36 & 6.9 & 251.2 & 150.3 & 1326.48 & 944.4 & 19.69 & 16.2 \\
\hline $1200 W B 342$ & 1416.65 & 6.26 & 252 & 141.3 & 1707.94 & 7.3 & 251.3 & 150.8 & 1421.73 & 950.6 & 19.71 & 16.8 \\
\hline $1200 W B 392$ & 1702.70 & 6.26 & 251.6 & 145.3 & 1959.11 & 7.6 & 252 & 150.2 & 1647.46 & 950.6 & 19.71 & 15.9 \\
\hline $1200 W B 423$ & 1880.70 & 6.22 & 251.1 & 147.7 & 2116.09 & 7.7 & 252 & 149.9 & 1765.49 & 956.8 & 19.73 & 16.6 \\
\hline $1200 W B 455$ & 2056.32 & 6.18 & 250.7 & 149.1 & 2273.07 & 7.8 & 251.4 & 151.1 & 1922.39 & 964.0 & 19.67 & 15.4 \\
\hline
\end{tabular}

As presented in Table 4, optimised CWBs have the section depth reduction percentages of between 19-20\%, which is a clear advantage over the standard WB. The optimisation process also achieved a substantial weight reduction in the range of $15-20 \%$ as shown in Table 4 . The mean and standard deviation of height reduction in Table 4 were 19.67 and 0.0766 respectively while the mean and standard deviation of mass reduction were 17.37 and 1.6151 , respectively. Apart from checking the limit states for strength and deflection in accordance with AS4100 (1998) as outlined earlier, an elastic critical buckling analysis was carried out on each CWB to ensure that no local buckling would take place as a result of the reduced thickness of the web. Table 5 presents the initial web thickness values obtained from Hot Rolled and Structural Steel Products property tables for welded beams (2018) and the reduced web thickness values of the optimised CWB's. It can be seen that all buckling load factors are greater than 1.0.

Table 5. Buckling analysis of optimised CWB.

\begin{tabular}{|c|c|c|c|}
\hline Designation & $t_{w \text { initial }}(\mathrm{mm})$ & $t_{w}$ reduced $(\mathrm{mm})$ & Buckling factor \\
\hline $700 C W B 115$ & 10 & 7.41 & 4.62 \\
\hline $700 C W B 130$ & 10 & 7.38 & 4.92 \\
\hline $700 C W B 150$ & 10 & 7.47 & 5.19 \\
\hline $700 C W B 173$ & 10 & 7.46 & 3.23 \\
\hline $800 C W B 122$ & 10 & 7.48 & 4.63 \\
\hline $800 C W B 146$ & 10 & 7.43 & 5.66 \\
\hline $800 C W B 168$ & 10 & 7.5 & 6.74 \\
\hline $800 C W B 192$ & 10 & 7.47 & 3.85 \\
\hline $900 C W B 175$ & 12 & 9.49 & 4.32 \\
\hline $900 C W B 218$ & 12 & 9.39 & 8.21 \\
\hline $900 C W B 257$ & 12 & 9.42 & 8.02 \\
\hline $900 C W B 282$ & 12 & 9.5 & 7.51 \\
\hline $1000 C W B 215$ & 16 & 13.38 & 4.62 \\
\hline $1000 C W B 258$ & 16 & 13.39 & 7.4 \\
\hline $1000 C W B 296$ & 16 & 13.41 & 8.5 \\
\hline $1000 C W B 322$ & 16 & 13.42 & 8.24 \\
\hline $1200 C W B 249$ & 16 & 13.45 & 8.63 \\
\hline $1200 C W B 278$ & 16 & 13.48 & 5.64 \\
\hline $1200 C W B 313$ & 16 & 13.46 & 6.45 \\
\hline $1200 C W B 342$ & 16 & 13.5 & 4.21 \\
\hline $1200 C W B 392$ & 16 & 13.45 & 3.58 \\
\hline $1200 C W B 423$ & 16 & 13.47 & 5.87 \\
\hline $1200 C W B 455$ & 16 & 13.48 & 6.28 \\
\hline
\end{tabular}




\subsection{Displacement limit states}

A comparison of the mid-span deflections of the standard WB and the optimised CBW is shown in Figure 7. It can be seen that all deflections fall well below the $20 \mathrm{~mm}$ limit, which for a $5 \mathrm{~m}$ long beam is the maximum allowable deflection of L/250 prescribed by AS4100.

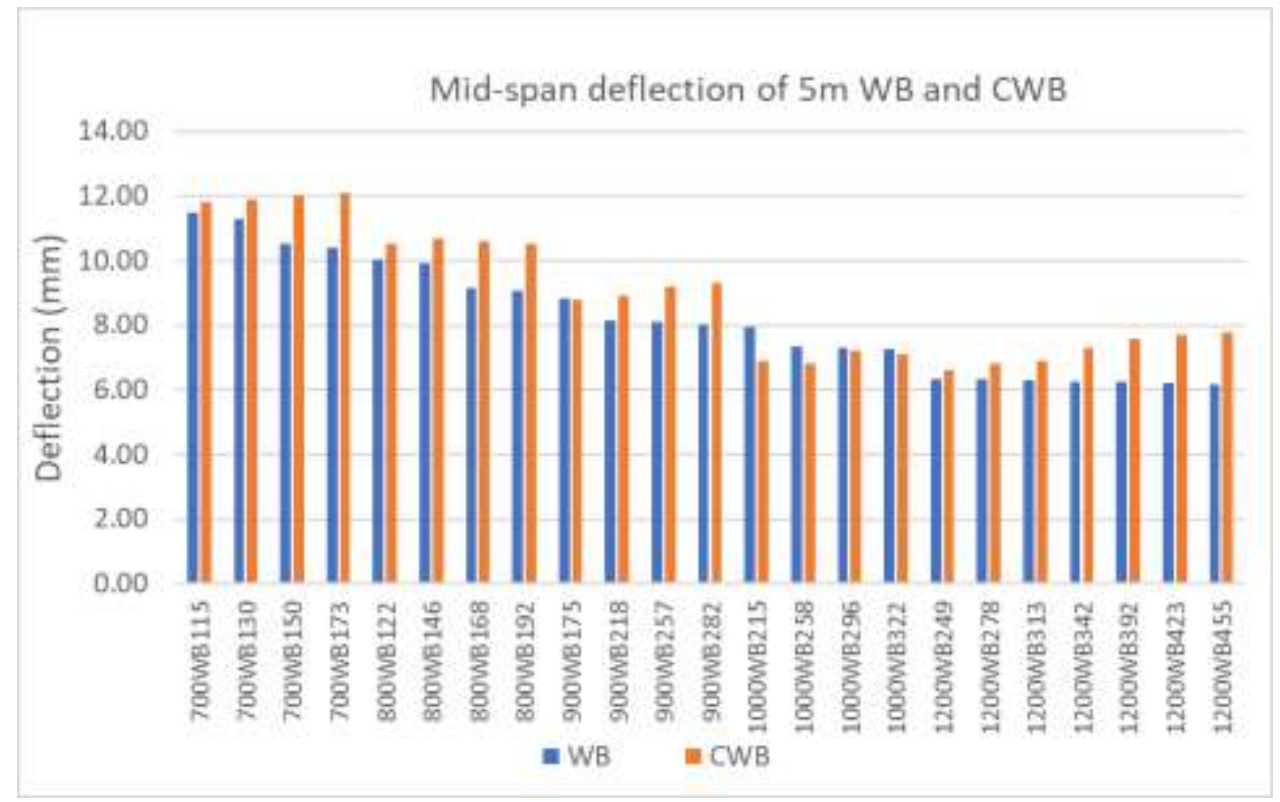

Figure 7. Deflection comparison between WBs and CWBs

\subsection{Proposed CWB Table for Dimensions and Cross Sectional Properties}

In order to design steel welded beams in Australia according to AS 4100 (1998), design engineers derive dimensions and cross sectional properties from Hot Rolled and Structural Steel Products property tables for welded beams (2018). Since a similar table has not yet been developed for corrugated welded beams in Australia, based on the results of this study, Table 6 has been developed and proposed as CWB table for dimensions and cross sectional properties. Moment of inertia $I_{x}$ and $\mathrm{I}_{\mathrm{y}}$ values in Table 6 have been calculated based on the relationship between $I$ and $\Delta_{\text {Max }}$ (Table 4) for simply supported beams in classical theory of mechanics. The new designations in Table 6 include the unit mass of the beam after CWB. For example, a $700 \mathrm{CWB} 96$ has $96 \mathrm{~kg} / \mathrm{m}$ unit mass.

The proposed table for dimensions and cross sectional properties can be employed in conjunction with Section 5 of AS 4100 (1998) for flexural design of steel beams as well as shear and bearing capacity checks.

Table 6. Proposed CWB table for dimensions and cross sectional properties

\begin{tabular}{ccccccccccccc} 
Designation & $\begin{array}{c}d \\
(\mathrm{~mm})\end{array}$ & $\begin{array}{c}b_{f} \\
(\mathrm{~mm})\end{array}$ & $\begin{array}{c}t_{f} \\
(\mathrm{~mm})\end{array}$ & $\begin{array}{c}t_{w} \\
(\mathrm{~mm})\end{array}$ & $\begin{array}{c}d_{l} \\
(\mathrm{~mm})\end{array}$ & $\begin{array}{c}A_{g} \\
\left(\mathrm{~mm}^{2}\right)\end{array}$ & $\begin{array}{c}I_{x} \\
\left(10^{6} \mathrm{~mm}^{4}\right)\end{array}$ & $\begin{array}{c}Z_{x} \\
\left(10^{3} \mathrm{~mm}^{4}\right)\end{array}$ & $\begin{array}{c}r_{x} \\
(\mathrm{~mm})\end{array}$ & $\begin{array}{c}I_{y} \\
\left(10^{6} \mathrm{~mm}^{4}\right)\end{array}$ & $\begin{array}{c}Z_{y} \\
\left(10^{3} \mathrm{~mm} m^{4}\right)\end{array}$ & $\begin{array}{c}r_{y} \\
(\mathrm{~mm})\end{array}$ \\
\hline 700 CWB96 & 557 & 250 & 16 & 7.5 & 525 & 11936 & 793 & 2847 & 258 & 52 & 416 & 66 \\
700 CWB104 & 562 & 250 & 18 & 7.5 & 526 & 12945 & 946 & 3367 & 270 & 60 & 480 & 68 \\
700 CWB124 & 571 & 250 & 23 & 7.5 & 525 & 15438 & 1054 & 3693 & 261 & 69 & 552 & 67 \\
700 CWB145 & 576 & 275 & 26 & 7.5 & 524 & 18233 & 1249 & 4334 & 262 & 89 & 647 & 70 \\
800 CWB97 & 636 & 250 & 15 & 7.5 & 606 & 12044 & 1063 & 3343 & 297 & 54 & 432 & 67 \\
800 CWB120 & 643 & 275 & 19 & 7.5 & 605 & 14988 & 1341 & 4172 & 299 & 71 & 516 & 69 \\
800 CWB138 & 651 & 275 & 23 & 7.5 & 605 & 17188 & 1517 & 4662 & 297 & 98 & 713 & 76 \\
800 CWB161 & 656 & 300 & 26 & 7.5 & 604 & 20133 & 1821 & 5549 & 301 & 143 & 953 & 84 \\
900 CWB140 & 722 & 300 & 18 & 9.5 & 686 & 17317 & 2104 & 5827 & 349 & 91 & 607 & 72 \\
900 CWB181 & 731 & 350 & 23 & 9.5 & 685 & 22608 & 2634 & 7205 & 341 & 173 & 989 & 87 \\
900 CWB212 & 735 & 400 & 25 & 9.5 & 685 & 26511 & 3148 & 8562 & 345 & 321 & 1605 & 110 \\
900CWB237 & 743 & 400 & 29 & 9.5 & 685 & 29704 & 3503 & 9435 & 343 & 350 & 1750 & 109 \\
1000 CWB172 & 802 & 300 & 18 & 13.5 & 766 & 21141 & 3312 & 8259 & 396 & 104 & 693 & 70 \\
1000 CWB213 & 811 & 350 & 23 & 13.5 & 765 & 26428 & 4154 & 10243 & 396 & 189 & 1080 & 85
\end{tabular}




\begin{tabular}{l|cccccccccccc}
1000 CWB250 & 816 & 400 & 26 & 13.5 & 764 & 31119 & 4776 & 11700 & 392 & 331 & 1655 & 103 \\
1000 CWB269 & 823 & 400 & 29 & 13.5 & 765 & 33522 & 5405 & 13141 & 402 & 368 & 1840 & 105 \\
1200 CWB201 & 939 & 275 & 23 & 13.5 & 893 & 24706 & 4341 & 9245 & 419 & 93 & 676 & 61 \\
1200 CWB229 & 939 & 350 & 23 & 13.5 & 893 & 28156 & 5025 & 10703 & 422 & 182 & 1040 & 80 \\
1200 CWB265 & 944 & 400 & 26 & 13.5 & 892 & 32847 & 5989 & 12683 & 427 & 324 & 1620 & 99 \\
1200 CWB284 & 951 & 400 & 29 & 13.5 & 893 & 35250 & 6321 & 13300 & 423 & 371 & 1855 & 103 \\
1200 CWB329 & 951 & 500 & 29 & 13.5 & 893 & 41050 & 7298 & 15354 & 422 & 660 & 2640 & 127 \\
1200 CWB353 & 957 & 500 & 32 & 13.5 & 893 & 44053 & 7956 & 16631 & 425 & 780 & 3120 & 133 \\
1200 CWB384 & 964 & 500 & 36 & 13.5 & 892 & 48042 & 8588 & 17816 & 423 & 821 & 3284 & 131
\end{tabular}

\subsection{Discussion}

Using the proposed table in this study enables Australian design engineers and engineering companies to not only save up to $20 \%$ of steel material but also substantially reduce the section depth of the beams. For instance, where a 700 WB115 is needed with the initial unit mass of $115 \mathrm{~kg} / \mathrm{m}$, an alternative $700 \mathrm{CWB} 104$ with unit mass of $104 \mathrm{~kg} / \mathrm{m}$ can be selected to provide equal capacity. In this case, the gross section depth of this CWB is only $562 \mathrm{~mm}$. This means $20 \%$ of the beam's section depth can be reduced. In the case of, for example, a 40-storey building, the total height of the beams will be reduced by $0.130 \mathrm{~m} \times 40=5.20 \mathrm{~m}$ over the entire height of the building compared to the use of $700 \mathrm{WB} 115$. Moreover, CWBs can reduce the use of the web stiffeners due to the corrugated shape of the web. Therefore, even more than $20 \%$ of the material weight could be saved in the design optimisation process using CWBs. Since Yu \& Xu (2013) pointed out that the manufacturing cost for CWBs is only $3 \%$ higher than the normal WBs with the same dimensions, it can be concluded that cost of manufacturing is relatively low so would not nullify the noticeable cost saving caused by using CWBs.

In the recent developments of the structural designs, one of the primary aims is to carry out more sustainable designs by reducing the usage of the constructional materials. To consider this strategy in protecting the environment, the reduced use of steel materials will indirectly help to reduce the $\mathrm{CO}_{2}$ emissions, since the manufacturing process of the steel beams results in a significant production of $\mathrm{CO}_{2}$. Therefore, since the global warming is defined as one of the severe issues for human beings, the use of CWBs can assist us reduce $\mathrm{CO}_{2}$ emissions and human footprint in order to contribute in mitigation of global warming.

\section{Conclusions}

In this study, a series of numerical analyses have been performed in order to investigate the structural behaviour of steel I girders with corrugated-web profile and to compare their mechanical performance with normal welded beams. Theory of Ultimate Limit State design has been used in accordance with AS4100 (1998) in this numerical investigation along with considering geometric and material non-linearity in the numerical analyses with SAP2000. Comparing the results of this numerical investigation, it has become apparent that corrugated welded beams (CWBs) have some merits over normal welded beams (WBs). In particular, by replacing WBs with CWBs with the same capacity, up to $20 \%$ of the material weight and one fifth of the beams section depth can be saved. This noticeable saving in the weight of steel material not only makes the design more cost effective and optimum but also indirectly contributes in reduction of $\mathrm{CO}_{2}$ emissions and human footprint. Reduction of the steel beams height could potentially create more available space for constructing additional building floors. Considering the high value of real estate in particular in large and populated cities (e.g. Sydney, Melbourne, etc) height reduction caused by the use of CWBs can contribute in more economical designs. In order to design steel welded beams in Australia according to AS 4100 (1998), design engineers derive dimensions and cross sectional properties from Hot Rolled and Structural Steel Products property tables for welded beams (2018). Since a similar table has not yet been developed for corrugated welded beams in Australia, based on the results of this study, CWB table for dimensions and cross sectional properties has been developed in this study and proposed for practical applications. 


\section{References}

Abbas H.H. 2003, 'Analysis and Design of Corrugated Web I-Girders for Bridges Using High-Performance Steel', PhD dissertation, Dept. of Civil and Environmental Engineering, Lehigh University.

Abbas H.H., Sause R., Driver R.G. \& Asce M. 2006, 'Behavior of Corrugated Web I-Girders under In-Plane Loads', Journal of Engineering Mechanics, Vol. 132, No. 8, pp. 806-814.

Alandkar P.M. \& Limaye A.A. 2013, 'Strength of Welded Plate Girder with Corrugated Web Plate', Journal of Engineering Research and Applications, Vol. 3, No. 5, pp. 1925-1930.

AS/NZS 1170.1 (2002) Australian/New Zealand Standard and supplement, Structural Design Actions - Part 1: Permanent, Imposed and Other Actions, Standard Australia, Sydney.

AS4100 (1998) Steel structures, Standard Australia, Sydney.

Ashrawi M.A., Sunitha C.M. \& Smitha K.K. 2016, 'Load Carrying Capacity of Corrugated Web Beams', International Research Journal of Engineering and Technology, Vol. 03, No. 09, pp.135-138.

Calenzani, A.F.G., Fakury, R.H., Fernando Paula, F.A., Rodrigues, F.C., Queiroz, G. \& Pimenta, R.J. 2012 'Rotational stiffness of continuous composite beams with sinusoidal-web profiles for lateral-torsional buckling', Journal of Constructional Steel Research, vol. 79, pp. 22-33.

Computers and Structures 2018, CSI Analysis Reference Manual for SAP2000, Berkeley, California. <http://docs.csiamerica.com/manuals/misc/CSI\%20Analysis\%20Reference\%20Manual\%202011-12.pdf >.

Divaha R. \& Joanna P.S. 2016, 'Investigation on the Behaviour of Encased Cold-formed Steel Beams with Trapezoidally Corrugated Web’, International Journal of Chemistry Science, Vol. 14, pp. 10-16.

Dubina D., Ungureanu V. \& Gilia L. 2015, 'Experimental Investigations of Cold-Formed Steel Beams of Corrugated Web and Built-up Section for Flanges', Thin-Walled Structures, Vol. 90, pp. 159-170.

Dunai L., Jáger B. \& Kövesdi B. 2016, 'Bending and Shear Interaction Behaviour of Girders with Trapezoidally Corrugated Webs', Journal of Constructional Steel Research, vol. 121, pp. 383-97.

Elgaaly M., Asce F., Seshadri A., Hamilton R.W. \& Asce M. 1997, 'BENDING STRENGTH OF STEEL BEAMS WITH CORRUGATED WEBS’, Journal of Structural Engineering, Vol. 123, No. 6, pp. 772-782.

Hot Rolled and Structural Steel Products, Welded Beams, viewed May 2018, https://www.libertyonesteel.com/media/165356/seventh-edition-hot-rolled-and-structural-steelproductsseventh-edition-hot-rolled-and-structural-steel-products.pdf

Hancock G.J. \& Pham C.H. 2012, 'Direct Strength Design of Cold-Formed I-Sections for Shear and Combined Actions', Journal of Structural Engineering, Vol.138, No. 6, pp. 759-768.

Huang L., Hikosaka H. \& Komine K. 2004, 'Simulation of Accordion Effect in Corrugated Steel Web with Concrete Flanges', Computers and Structures, Vol. 82, pp. 2061-2069.

Jiang J., Li G., \& Zhu Q. 2015, 'Local buckling of compression flanges of H-beams with corrugated webs', Journal of Constructional Steel Research, vol. 112, pp. 69-79.

Ju G., Luo X., Sun F., \& Fan X. 2014, 'Experimental Investigation on Fatigue Performance of Welded H-beam with Corrugated Webs', Journal of Building Structures, Vol. 5, No. 1, pp. 96-103 (in Chinese).

Kovesdi B. 2010, 'Patch Loading Resistance of Girders with Corrugated Webs', PhD Dissertation, University of Stuttgart, Germany.

Lukin A \&. Shlyakhin D. 2016, 'A Flexible Beam with Corrugated Web and Its Performance under Bending: An Experimental Study', MATEC Web of Conferences, Vol. 86, pp. 44-53.

Martins, A. G., Fakury, R.H, Pimenta, R. J., Queiroz, G. \& Rodrigues, F.C. 2012 'Moment resistance of composite steel and concrete connection in sinusoidal-web girders', Journal of Constructional Steel Research, vol. 76, pp. 112-120.

Oliveira, J.P.S., Calenzani, A.F.G, Fakury, R.H., Ferreira, W. 2016 'Elastic critical moment of continuous composite beams with a sinusoidal-web steel profile for lateral-torsional buckling', Engineering Structures, vol. 113, pp. 121-132. 
Tabatabaiefar, H.R, Fatahi, B., Ghabraie, K. \& Zhou, W. 2015, 'Evaluation of Numerical Procedures to Determine Seismic Response of Structures under Influence of Soil-Structure Interaction', Structural Engineering and Mechanics, vol. 56, no. 1, pp. 27-47, Techno Press.

Tabatabaiefar, H.R \& Mansoury, B. 2016, 'Detail Design, Building and Commissioning of Tall Building Structural Models for Experimental Shaking Table Tests', The Structural Design of Tall and Special Buildings, vol. 25 , no. 8, pp. 357-374.

Tang Y. \& Wan S. 2012, "Innovative Practice of Prestressed Concrete Box-Girder Bridges with Corrugated Steel Webs", Henan Provincial Communications Planning Survey \& Design Institute Co.Ltd, Henan China, viewed at $16^{\text {th }}$ September 2017, (in Chinese). http://www.hnrbi.com/kcsjy/html/737/3373/2012-529/179536.html.

Walsh, P., Saleh. A. and Far, H. 2018 'Evaluation of Structural Systems in Slender High-rise Buildings', Australian Journal of Structural Engineering, vol. 19, no. 2, pp. 105-117.

Yu, H. \& Xu, H. 2013, 'Characteristics and Forward Research of the Corrugated-Web H beams', Zhejiang Jinggong Science \& Technology Co., Ltd, China, viewed at 3th July 2018 (in Chinese), https://wenku.baidu.com/view/8efc12f750e2524de4187e15.html.

Yazeed E. S. 2007, 'Design Aspects of Steel I-Girders with Corrugated Steel Webs', Electronic Journal of Structural Engineering, Vol. 7, pp. 27-40. 